\title{
Effect of the Pandemic and Lockdown on Mental Health of Children
}

\author{
Kalpna Thakur ${ }^{1} \cdot$ Naveen Kumar $^{2} \cdot$ NovRattan Sharma ${ }^{1}$
}

Received: 4 April 2020 / Accepted: 14 April 2020 / Published online: 12 May 2020

(C) Dr. K C Chaudhuri Foundation 2020

To the Editor: In response to COVID-19 outbreak, Indian government recently announced lockdown of $21 \mathrm{~d}$ which surely is going to reduce the transmission rate of SARSCoV-2. However, this lockdown has restricted people to stay at home which is likely to impact their physical as well as mental health. Especially vulnerable to this are children. Particularly those whose parents are either affected by COVID-19 or are rendering their services in hospitals or those who are affected or had exposure to this virus and quarantined therefore. It has been found that children staying at home due to lockdown spend more time in front of TV and internet which can lead to psycho-social problems, like lower selfesteem [1]. Excess use of internet can lead to internet addiction disorder. Some can also experience cyberbullying which can affect their mental health. Moreover, spending more time inside the house makes children vulnerable to effects of indoor pollution which can affect their brain development leading to limited development of cognitive abilities [2]. Liu et al. suggests that children who are separated from their parents/ caregivers due to their infections or their parents being affected or their parents serving in hospitals are more susceptible to psychological problems. Their vulnerability to depression, stress, anxiety, avoidance behavior, and post-traumatic stress disorder have been reported [3]. Infant's development of attachment to their caregivers can be affected by their separation which is crucial for the child psychological wellbeing in the adulthood [4]. Though, great efforts have been made by Indian government to combat this pandemic, however, this will lead India half way only as we need to focus on holistic health of children and not focusing only on providing basic

Kalpna Thakur

kashipuni3@gmail.com

1 Department of Psychology, Maharishi Dayanand University, Rohtak, Haryana 124001, India

2 Department of Physics, National Institute of Technology, Hamirpur, Himachal Pradesh, India care. For this we suggest, the parents of children staying at home should reduce their use of internet and TV by engaging them in physical activities. Children who are separated from their parents should be given special care. Their nutritional needs should be taken care of. Their communication with parents should be increased via phone and their access to mental health services should be improved. For this, throughout India, various psychological associations have come forward to provide counselling services through telephone. We suggest efforts like these should be encouraged.

\section{Compliance with Ethical Standards}

Conflict of Interest None.

\section{References}

1. Grechyna D. Health threats associated with children lockdown in Spain during COVID-19. SSRN. 2020. https://doi.org/10.2139/ ssrn.3567670.

2. Franklin PJ. Indoor air quality and respiratory health of children. Paediatr Respir Rev. 2007;8:281-6.

3. Liu JJ. Mental health considerations for children quarantined because of COVID-19. Lancet Child Adolesc Health. 2020. https://doi.org/ 10.1016/S2352-4642(20)30096-1.

4. Humphreys KL. Future directions in the study and treatment of parent child separation. J Clin Child Adolesc Psychol. 2019;48:166-78.

Publisher's Note Springer Nature remains neutral with regard to jurisdictional claims in published maps and institutional affiliations. 